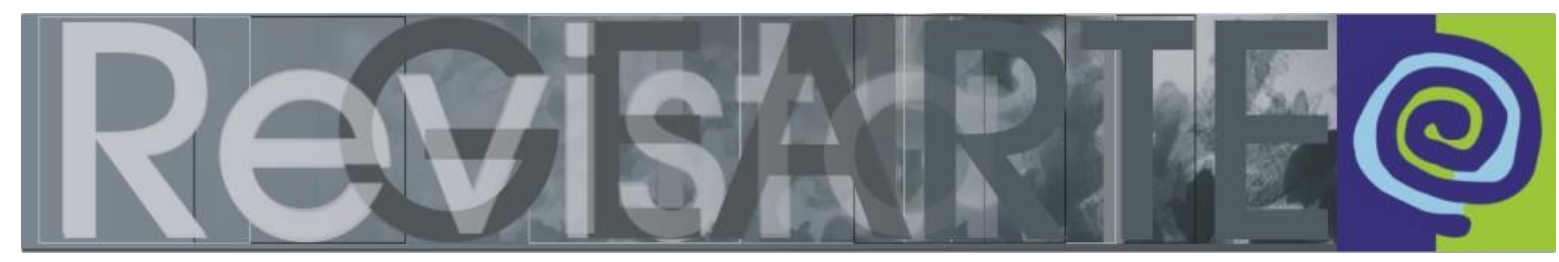

Volume 1, Número 2, Agosto/2014, ISSN 2357-9854

\title{
Encontros da arte e do museu com a educação: momentos de encantamento e reflexão
}

\author{
Adriana Aparecida Ganzer (UNESC - Brasil) \\ Maria Isabel Leite (UNESC - Brasil)
}

\section{RESUMO}

Este artigo apresenta algumas importâncias atinentes ao museu identificado como espaço de produção de conhecimento permeado por narrativas, memórias e descobertas. Conta fragmentos de uma pesquisa de mestrado na qual experiências estéticas emergiram a partir de relações estabelecidas entre crianças, adultos, patrimônio e espaço social em visitas a instituições museais. Questiona possibilidades de conexões entre as instituições de ensino não formal e formal em reflexões constituídas com Benjamin (1994), em diálogo com crianças, poetas (Manoel de Barros), teóricos da infância, da educação (Leite 2008; Sarmento 2007; Ostetto 2006) e das questões museais como Chagas $(2013,2009)$. Dentre as considerações evidencia o olhar que se sensibiliza no encontro entre espectador e arte; e para a desconstrução/construção de recomendações na visita mediada aos espaços expositivos.

\section{PALAVRAS-CHAVE}

Museu de arte; educação museal; pesquisa com crianças.

\section{ABSTRACT}

This article presents some issues related to the museum identified as a space of knowledge production permeated by narratives, memories and discoveries. Counts with fragments of a research for a dissertation in which aesthetic experiences emerged from relationships established between children, adults, patrimony and social space in visits to museums. Questions possibilities of connections between the institutions of non-formal and formal education through reflections by Walter Benjamin, in dialogue with children, poets (Manoel de Barros), theorists in childhood, education (Leite, Sarmento, Ostetto) and in museological issues, such as Mario Chagas. The considerations demonstrate the look that are sensitized in the encounter between viewer and art; and the deconstruction/construction of the recommendations in the mediated visit to exhibition spaces.

\section{KEYWORDS}

Museum of Art; museum education; research with children.

\section{Perspectivas e entrelaçamentos}

[...] quem se recolhe diante de uma obra de arte mergulha dentro dela e nela se dissolve.

Walter Benjamin

No desejo de aprofundar questões educativas atinentes ao museu de arte a partir do olhar da criança e da multiplicidade perceptiva de sua imaginação, apresento, 
aqui, fios entrelaçados de uma pesquisa ${ }^{1}$ na qual crianças e eu, experimentamos maneiras distintas de olhar para a arte, para os museus de arte e seus serviços educativos. Sigo o caminho da curiosidade e da imaginação para estabelecer uma relação dialógica entre o museu de arte e as crianças participantes. Nessa direção menciono parte dos relatos transformados em diálogos e narrativas tecidas a partir desta mirada.

As reflexões foram elaboradas a partir de Benjamin (1994) em diálogo com crianças, poetas como Manoel de Barros (2006), teóricos da infância, da educação como Leite (2008), Sarmento (2007) e Ostetto (2006) e de questões museais como Chagas $(2013,2009)$. Olhares e diálogos foram estabelecidos em conversas com crianças nas quais registrei suas considerações, suas críticas, suas dúvidas e suas sugestões acerca de uma questão central: como elas imaginam e elaboram considerações referentes à arte e ao espaço museal a partir da visita ao museu.

Tomo como referência Benjamin (1994) que, ao falar da arte de narrar, aponta que perdemos a capacidade de ouvir o outro, de comunicar nossas experiências, de apreciar as particularidades do olhar do outro pela sua narrativa. Interessado na cultura e na história pontua que o narrador retira da experiência o que ele conta e congrega as coisas narradas com o conhecimento dos seus ouvintes, "assim se imprime na narrativa a marca do narrador, como a mão do oleiro na argila do vaso" ( $p$. 205).

Espaços de narrativa ${ }^{2}$ foram criados no intento de promover a aproximação e ouvir suas percepções sobre e a partir do trabalho educativo realizado no museu. Esses que são espaços de produção de conhecimento, segundo Leite (2008, p. 120) "são estratégias teórico-metodológicas de investigação", que se constituem e se consubstanciam no seu caminhar, compreendidas como fundamentais para provocar reflexões e descobertas. Assinalo que alimentar a imaginação da criança ao criar espaços de narrativa é uma forma de promover sentidos outros para além do que já

\footnotetext{
${ }^{1}$ A pesquisa aconteceu em momentos de conversas em escolas antes e após a visita e nos espaços expositivos; os educativos investigados foram do Museu de Arte do Rio Grande do Sul - MARGS, do Santander Cultural e da Fundação Iberê Camargo em Porto Alegre - RS - Brasil. Dessa atividade resultou a Dissertação de Mestrado.
}

2 Por esta ser uma expressão cunhada a partir de discussões metodológicas de pesquisa, ela aparece em itálico. Para saber mais sobre os espaços de narrativa ver Leite (2008). 
está estabelecido, é permitir que as crianças mostrem suas capacidades, como também é construir espaços de trocas que permitam expressar seus sentimentos, sensações, ideias e concepções que dizem respeito ao espaço do museu e ao encontro com as obras de arte na sua forma original.

\section{Ampliar o conhecimento cultural, imagético e sensorial na formação do olhar}

Assinalo os momentos em que conversei com as crianças acerca da arte, do museu de arte, das suas expectativas e imaginações, posto que percebi o quanto isso se tornou valioso para mim e também para elas e, portanto, me questiono sobre como estimular e intensificar a relação com a arte, com o museu, com a educação e com a vida desses meninos e meninas? Como elas descobrem a arte? Como acontece a experiência estética? É possível entrelaçar afinidades entre a arte e as instituições de ensino não formal (os museus de arte) com as instituições de ensino formal (as escolas)? Como ampliar os olhares e a percepção das crianças fruidoras?

Sarmento ${ }^{3}$ fala que o modo como as crianças de diferentes classes sociais, culturais e em alguns casos étnicos "interatuam, representam a si próprias e representam os outros e como isso se configura numa consciência de si enquanto cidadãs do mundo, é o modo como as crianças produzem e se constituem como atores culturais". Nesse sentido, o menino Valdecir, em um de nossos encontros, disse o seguinte: "Foi uma pena não ter tirado fotos minhas lá no museu mansão! la ser uma boa recordação, tão grande, tanta escada. Tenho uma história para contar e um dia eu quero voltar lá". Saliento essa fala, pois, para o menino que foi ao museu pela primeira vez, a experiência é impregnada pelo encanto, pela curiosidade, pelo devaneio e pelo encontro com novas possibilidades para além da sala de aula, a descoberta de um espaço outro - o espaço museal.

Discutirmos arte com as crianças revela suas ideias, sua imaginação, seu pensamento e compreende um universo maior, pois, visitar uma exposição de arte é uma oportunidade para ampliar o conhecimento cultural, imagético e sensorial na formação do olhar. Aos olhos do contemplador, os saberes são ressignificados e, numa combinatória de experiências, novos olhares são produzidos. Outrossim, ao

\footnotetext{
${ }^{3}$ Palestra proferida na Faculdade de Educação da UFRGS em 13 de abril de 2007 - anotações pessoais.
} 
entender que a arte adquire o caráter de obra quando cria uma relação com o espectador-fruidor, as exposições apontam caminhos para uma mudança de percepção e promovem a aproximação. Para Benjamin (1994), a ampliação da significação social da arte reduz as distâncias, bem como produz uma atitude crítica de fruição para com o que é percebido e que nos atinge.

Intensifico a necessidade de repensar, de forma ampliada, as condições de interação entre a arte, a criança e o museu de arte, na oportunidade de enlaçar as teorias da arte e da infância com o imaginário compreendido nas suas vozes. Cito uma fala que foi mais ou menos assim: "Isso aqui parece desenho de criança, e ali, ó, ela usou errorex [marca de corretivo]. Ela não é uma artista?". Referindo-se a alguns desenhos $^{4}$ feitos com giz de cera que estavam no segundo andar do museu: "Arte é assim, quando a gente olha... pensa coisas, de cabeça. Ô, eu queria poder ver mais arte". E ainda a criança comentou que a arte é mais bonita quando a gente entende, e eu questionei: e quando não entende? - "Daí é de imaginar".

\title{
Expectativas no espaço museal e o possível despraticar das normas
}

\author{
Adriana: E o que vocês imaginam que vai acontecer lá, será que alguém vai \\ receber vocês? \\ Eduarda: Eu acho que vai ter coisas diferentes. \\ Gabriel: Eu acho que vai ter um homem que vai estar lá na porta mostrando \\ as coisas. \\ Guria: Vai ter um monte de câmeras. \\ Adriana: Ah é? Vai ter câmera pra quê? \\ Crianças: Pra espiar. Pra ver se alguém vai mexer... \\ Adriana: Pode mexer? \\ Crianças: Não! Porque daí estraga.
}

Considero o espaço museal (de arte) um local mágico e desafiador, que conta a história da arte e dos artistas na formação da nossa história e da nossa cultura, como também provoca o gosto pela descoberta das impressões sensoriais, 0 assombro e o encantamento pela linguagem visual. Para Chagas $(2009$, p.55) "olhar efetivamente um museu é também se perceber olhado, olhar efetivamente um objeto de um museu é saber-se olhado por ele".

Igualmente é sabido que o espaço não apenas determina o olhar, mas exige regras diferenciadas de comportamento. A maioria das crianças já tinha informações

\footnotetext{
${ }^{4}$ Exposição da artista Vera Chaves Barcellos - O Grão da Imagem.
} 
dadas pelos professores a respeito do tipo de cuidados a serem tomados quando se vai ao museu, ou seja, sobre as faixas em frente às obras para não se aproximarem muito e também não tocarem, bem como: não correr, não tocar, não gritar... As próprias crianças já vigiavam os colegas neste sentido: - "Tira o dedo daí!"; "Ô, não mexe!"; "Ih, te comporta meu! Ah, tinha que ser... Fica quieto!"; "Olha com os olhos...”; "Como tu é curioso, fica quieto"; "Aquele ali, ó, é muito brincalhão, mas ele se comporta...".

Nesse sentido, ao considerar essas recomendações já interiorizadas pelas crianças, me questiono: seria possível pensar na comunicação da arte com as crianças espectadoras e despraticar ${ }^{5}$ as normas adotadas pelos serviços educativos dos museus? Poderíamos pensar em relações das crianças com as obras de arte e ao mesmo tempo respeitarmos os preceitos museológicos? Inspirada na perspectiva do narrador benjaminiano observo as histórias tecidas e descrevo dois exemplos em que a possibilidade de despraticar o já estabelecido e dito no início da visita causou estranhamento e grande espanto para as turmas.

No momento em que as crianças são recebidas, acontece uma conversa atinente às normas museais. Inicialmente, destaco uma turma que foi ao Museu de Arte do Rio Grande do Sul - MARGS para conhecer obras do artista plástico lberê Camargo $^{6}$ que estavam expostas lá. As crianças foram recepcionadas por uma mediadora do museu que deu as boas vindas, contou um pouco sobre a instituição, sua fundação, o prédio histórico e também passou algumas dicas de visitação: explicou que estavam em um museu de arte e que não poderiam comer e, principalmente, não poderiam tocar nas obras. Ela explicou um pouco sobre a conservação das obras e avisou que, se todos as tocassem, o contato dos nossos dedos poderia danificá-las. Após esse preâmbulo, passou o grupo para os mediadores da Fundação Iberê Camargo.

Vale salientar que essa exposição estava composta de duas salas: a primeira com gravuras em metal do artista, que todos observaram respeitando as indicações

\footnotetext{
${ }^{5}$ Manoel de Barros (2006), nas suas Memórias inventadas: a segunda infância anota que teve uma namorada que "via errado. (...) Ela despraticava as normas. Dizia que seu avesso era mais visível do que um poste. Com ela as coisas tinham que mudar de comportamento" (fragmento XII).

${ }^{6}$ Vale destacar que o Museu Iberê Camargo estava em construção no momento da pesquisa (2007) e que inaugurou sua nova sede em maio de 2008. Para saber mais acessar: www.iberecamargo.org.br.
} 
estabelecidas. Contudo, na outra sala encontramos obras realizadas por artistas que trabalharam no atelier de Iberê $^{7}$ e traziam características diferenciadas na sua elaboração, pois foram criadas para serem tocadas. A mediadora reuniu a turma ao redor de uma mesa na qual estavam as obras e pediu que uma das crianças fizesse sua intervenção, ou seja, mexesse na obra. Silêncio total! Quem se atreveria, posto que tantas recomendações foram dadas? Aos poucos a turma se soltou e interagiu. Perguntei a elas como era a sensação de poder tocar e, mais que isso, modificar uma obra no museu. As respostas foram muitos sorrisos e declarações - "É muito maneiro"; "É show de bola, olha que bala!"; "Adorei esta experiência”.

Com essa turma em outro momento na escola, retomamos esse assunto. Para a Camila, foi "interessante terem falado as regras". Já para o Tiago, "a Camila sempre vem com regras...". Mas foi o Alan quem concluiu: "Ter regras é bom, porque senão, como ia ter ordem? Por exemplo, não tocar, não chegar muito perto... sem regras é difícil controlar as coisas". Esse diálogo me fez perguntar: "Mas lá no museu, teve um momento diferente disso e vocês mexeram nas obras... Como foi?". Para a Laynara, a experiência foi "original! Brinquedos de artes. Eu brinquei com o quebra-cabeça ${ }^{8}$ de pano". Já Sabrina apontou: "Legal! Daí tu sente assim a obra!". Várias crianças também disseram que gostaram de brincar com a obra: "Tinha umas bolinhas coloridas, ${ }^{9}$ dava pra escrever o nome, por exemplo. Ou dava pra fazer desenhos...". “Adriana escreve também: Gostei do artista! Eu sei, era lberê Camargo!”.

A segunda turma a despraticar as normas foi ao Santander Cultural. $\mathrm{Na}$ acolhida também receberam indicações sobre cuidados e preservação com as obras e o espaço. Apesar disso, na mostra da artista Vera Chaves Barcellos ${ }^{10}$, faziam parte de uma das obras várias pequenas caixas de madeira contendo gravuras de flores. Essas caixas estavam dispostas em bancadas, acompanhadas por um par de luvas brancas. As crianças, então, tiveram a experiência de vestir as luvas, abrir as caixas e folhear as páginas para observar as imagens impressas. Ao questionar um menino se isso era possível, ele prontamente pediu desculpas e me respondeu que outros

\footnotetext{
${ }^{7} \mathrm{O}$ atelier de gravura se mantém em atividades mesmo após a morte de lberê Camargo em 1994.

8 Obra da artista plástica Lucia Koch.

9 Obra do artista plástico Nelson Leirner.

${ }^{10}$ Idem nota de rodapé 5.
} 
colegas também estavam fazendo. Pedi que ele ficasse tranquilo, pois as luvas estavam ali para que as pessoas pudessem mexer nas obras. "Ufa, que alívio! Até levei um susto. Mas é muito chique ver assim, com luvas brancas!" (Valdecir). Em outro momento de conversa na escola a turma se pronunciou:

\author{
Vanessa: Tinha um monte de coisas assim, umas folhas que, pra olhar, tinha \\ que botar umas luvas pra não ficar as digitais. \\ Adriana: Luvas brancas! Quem botou as luvas brancas? \\ Vanessa: Eu! E meu dedo ficou branco. [risos] \\ Valdecir: Eu já falei. \\ Adriana: Ah, sim! Vocês já tinham colocado luvas brancas? \\ [risos] \\ Adriana: E por que as luvas brancas do lado da obra? \\ Vanessa: Pra não deixar as digitais. \\ Valdecir: Pra não sujar o papel. \\ Adriana: Será que sempre tem luvas brancas lá? \\ Vanessa: Não! Não pode mexer. É só pra olhar com os olhos. \\ Adriana: E que sensação foi essa de mexer numa obra no museu? \\ Carla: Interessante! Deu pra ver uma coisa bem legal, os detalhes.
}

Um dos pontos dignos de nota foi perceber que aconteceram vários tipos de recepção e de mediação, isto é, a presença dos mediadores determinou o estilo da visita e, decorrente disso, o tipo de conhecimento e forma como foi produzido. As propostas museológicas organizadas com obras para serem tocadas causaram experiências estéticas diferenciadas, mesmo contrárias às normatizações, surgiram como elementos que potencializaram a visita. Nessa perspectiva, pergunto: como o trabalho realizado pelo serviço educativo pode interagir e desafiar o espectador, aproximar os conceitos e permitir a fruição e o defrontar-se com o mistério concernente às obras de arte? Como pode proporcionar que aconteça o diálogo e a abertura ao encontro e a interpretação para além da própria obra? A organização museológica pode contribuir? Segundo Ostetto (2006, p. 31), esse encontro é intenso, pois "o que se passa entre uma pessoa e uma obra será sempre mais secreto, mais complexo que o dizível".

Isso se alicerça nas diferentes concepções que permeiam a ação educativa concepções de museu, de arte, de infância, de produção de conhecimento. Consequentemente, essas concepções marcam a forma como as crianças são recebidas no museu; a maneira como o diálogo com elas é estabelecido e acolhido. 
Sobre suas concepções de museu, mesmo que distante para a maioria das crianças, ${ }^{11}$ não percebi falas das crianças atinentes a não saber o que é um museu; e raramente foi dito como um lugar de coisa velha. As respostas muito comumente eram construídas com questões, que giraram mais em torno do que poderiam fazer no museu, como, por exemplo: "Será que dá pra brincar lá?"; "Tem espaço para as crianças?"; "Tem esqueleto de dinossauro?"; "Tem roda gigante?". Para essas tantas crianças com quem conversei, o museu é um local que guarda coisas valiosas, e ao conhecerem os espaços, a sensação mais provocada foi de encantamento: "Lá tem letras de outros países, ih, tem um montão de coisas".

As concepções de arte inicialmente trazidas à tona estavam somente relacionadas com aquelas trabalhadas pela escola. Entretanto, percebi que aos poucos, a partir das experiências no museu e dos debates feitos, esses conceitos foram se ampliando e as próprias crianças estabeleceram percepções outras, ou seja, o que antes se reduzia a desenho colorido e pintura foi ampliado. Sendo assim, com o objetivo de intensificar as diferentes conceituações de arte que me foram ditas, retomo aqui algumas das tantas falas definidas pelas crianças: "Desenhos"; "Estátuas"; "Coisas enfeitadas"; "Coisa de tinta"; "Coisas valiosas"; "Pra se emocionar!"; "A gente pode ver obras de arte nos filmes, cinema também é arte"; "É tipo uma nuvem assim, fazer desenhos das nuvens..."; "Arte eu acho que é poesia"; "Arte vem de dentro!"; "Arte é de aprender"; "Arte é cultura!".

\section{Saberes impregnados de diálogos e percepções museais}

Nessa faculdade de intercambiar experiências, posso dizer que é fascinante perceber, nas falas, a forma como elaboram seu pensamento; adentram na fala do outro, incorporam e somam, tecendo uma rede de saberes e descobertas. As crianças são sempre muito observadoras, muitas vezes no nosso olhar adulto nós não percebemos o quanto elas estão atentas. Entendi que elas encararam a ida ao museu como uma atividade educativa mesmo que citassem anteriormente perspectivas para além do conceito ensino-aprendizagem, como os brinquedos e brincadeiras que poderiam, ou não, acontecer na visita - mais do que isso, compreendi que para elas

\footnotetext{
${ }^{11}$ Distante de sua realidade e longe fisicamente - ouvi inúmeros comentários de que aquela poderia ser a primeira e única visita.
} 
o mais importante foi o que ficou na sua imaginação e agora na sua percepção museal. "No meu museu ia ter coisas divertidas"; "Uma festa no museu!".

Em nossos encontros, falamos e ouvimos uns aos outros, paramos para pensar como as crianças imaginavam os museus de arte e o que elas almejavam dessa experiência. O poeta Manoel de Barros (2006, p.3), fala de "uma infância livre e sem comparamentos". Nessa direção penso em quantas peraltagens ${ }^{12}$ museais ainda poderemos fazer para aproximar, museus, crianças, arte e educação, já que "a importância de uma coisa há que ser medida pelo encantamento que a coisa produza em nós" (BARROS, 2006, p. 9).

Acredito que assim que obtivemos comunhão entre museu, educação e espectadores-fruidores, interligamos ideias, vislumbramos caminhos, ousamos imaginar e, nesse diálogo provocado, aprendemos muito, as crianças e eu.

Destarte, esses momentos pautados pela experiência de ver e ao despraticar as normas rever e até mesmo transver ${ }^{13}$ com as possibilidades do toque e das manipulações, suscitam mais questionamentos se concentrarmos nosso pensamento na transgressão e propormos aos apreciadores, sejam crianças e ou adultos, experimentações estéticas diferenciadas a partir das concepções da própria arte pelos artistas e da organização museal. Trânsitos entre o deleite e a ludicidade.

Essa minha exultação crianceira se aproxima do poeta Manoel de Barros que encontra palavras e expressões que permitem o sentido do encantamento que se propagou nessa pesquisa que não encerrou e segue me desacomodando a pensar e repensar na comunicação da arte com as crianças espectadoras e em como podemos possibilitar esse despraticar das normas nos espaços musealizados. Um desafio, sem dúvida para o modo de elaborar as exposições para que essas possam desafiar os espectadores-fruidores e proporcionar uma aproximação maior - e quem sabe um diálogo mais próximo - com o mistério instigante das obras de arte.

Ademais, fica o pensamento para que possamos pensar e criar estratégias para que os serviços educativos elaborem alternativas que possam aproximar a fruição ao

\footnotetext{
12 Termo criado por Manoel de Barros.

13 Idem nota anterior.
} 
mesmo tempo em que ponderem com as questões patrimoniais exigidas e tão importantes aos museus e centros culturais. Conforme Chagas (2013, p. 28), o desafio que importa encarar é "trabalhar a poética do museu e a poética do patrimônio", o que implica também "aceitar um conhecimento que se produz fora da disciplina, uma espécie de imaginação museal ou pensamento selvagem que se movimenta fora do controle e se preciso contra a disciplina e o controle". Está posto o desafio. O museu é um veículo de comunicação e de humanização. Chagas (2013, p.30) menciona o poeta Manoel de Barros ao dizer de uma lição (ou deslição) que pressupõe "um olhar compreensivo e compassivo para os inutensílios musealizados e para o patrimônio inútil da humanidade. (...) Devorar e ressignificar os museus, eis o desafio de cada nova geração".

\section{Referências}

BENJAMIN, Walter. Obras escolhidas. Magia, técnica, arte e política. São Paulo: Brasiliense, 1994.

BARROS, Manoel de. Memórias inventadas: a segunda infância. São Paulo: Editora Planeta do Brasil, 2006.

CHAGAS, Mário. A imaginação museal: museu, memória e poder em Gustavo Barroso, Gilberto Freyre e Darcy Ribeiro. Rio de Janeiro: MINC/IBRAM, 2009.

CHAGAS, Mário. Educação, museu e patrimônio: tensão, devoração e adjetivação. In: TOLENTINO, Atila Bezerra (Org.). Educação patrimonial: educação, memórias e identidades. João Pessoa: Iphan, 2013. p. 27-31. (Caderno Temático 3)

GANZER, Adriana Aparecida. "Eu começava a olhar uma coisa que me interessava e já tinha que olhar outra": refletindo sobre a relação dialógica entre o museu de arte e a criança. Criciúma, 2008. 154 p. Dissertação de Mestrado. UNESC, Criciúma, 2008.

LEITE, Maria Isabel. Espaços de narrativa - onde o eu e o outro marcam encontro. In: CRUZ, Silvia Helena Vieira (Org.). A criança fala: a escuta de crianças em pesquisas. São Paulo: Cortez, 2008. p. 118-140.

OSTETTO, Luciana. A arte no itinerário da formação de professores: acender coisas por dentro. Reflexão e ação, Santa Cruz do Sul, v. 14, n.1, p. 29-43, jan./jun 2006.

SARMENTO, Manoel Jacinto. Culturas infantis e interculturalidade. Palestra proferida na Faculdade de Educação da UFRGS em 13 de abril de 2007 - anotações pessoais.

\section{Adriana Aparecida Ganzer}

Mestre em Educação pela Universidade do Extremo Sul Catarinense - UNESC (2007). Graduada em Artes Plásticas - Licenciatura e Bacharelado - UPF (1993). Integrante do Projeto "Cidade das Crianças", UFRGS/ GEARTE/ Usina do Papel/ Usina do Gasômetro. Pesquisadora do GEDEST Grupo de Pesquisa, Ensino e Extensão em Educação Estética/ UNESC. Experiência na área de Arte, Infância e Educação formal e não formal.

E-mail: aaganzer@gmail.com

Currículo: http://lattes.cnpq.br/2531849773615856 


\section{Maria Isabel Leite}

Pós-Doutorado em Arte-Educação pela Roehampton University, Londres (2007). Doutorado em Educação pela UNICAMP (2001), mestrado em Educação (1995) e graduação em Pedagogia (1985) pela PUC-Rio. Foi uma das fundadoras e coordenadora do Museu da Infância, de 2005 ao final de 2010. Pesquisadora e consultora autônoma na área de educação e infância, espaços formais e não formais de educação.

E-mail: leite.mariaisabel@gmail.com

Currículo: http://lattes.cnpq.br/1521138877751994 